|| ISSN(online): 2589-8698 || ISSN(print): 2589-868X || International Journal of Medical and Biomedical Studies

Available Online at www.ijmbs.info

PubMed (National Library of Medicine ID: 101738825)

Index Copernicus Value 2018: 75.71

Volume 3, Issue 4; April: 2019; Page No. 223-228

\title{
A STUDY TO COMPARE CAUDAL DEXMEDETOMIDINE VERSUS FENTANYL AS ADJUVANT TO 0.25\% LEVOBUPIVACAINE FOR POSTOPERATIVE SEDATION IN PAEDIATRIC PATIENTS UNDERGOING INFRAUMBLICAL SURGERIES UNDER GENERAL ANAESTHESIA
}

\author{
Kanchan Chauhan ${ }^{1}$, Roma Sharma ${ }^{2}$ \\ ${ }^{1}$ Professor, ${ }^{2}$ Junior Resident, \\ SMS Medical College, Jaipur, Rajasthan
}

Article Info: Received 15 April 2019; Accepted 29 April. 2019

Cite this article as: Chauhan, K., \& Sharma, R. (2019). A STUDY TO COMPARE CAUDAL DEXMEDETOMIDINE VERSUS FENTANYL AS ADJUVANT TO 0.25\% LEVOBUPIVACAINE FOR POSTOPERATIVE SEDATION IN PAEDIATRIC PATIENTS UNDERGOING INFRAUMBLICAL SURGERIES UNDER GENERAL ANAESTHESIA. International Journal of Medical and Biomedical Studies, 3(4).

DOI: https://doi.org/10.32553/ijmbs.v3i4.225

Address for Correspondence: Junior Resident, Roma Sharma, SMS Medical College, Jaipur, Rajasthan Conflict of interest: No conflict of interest.

\section{Abstract}

Background: Caudal analgesia reduces the amount of inhaled and intravenous (i.v.) anaesthetic requirement, attenuates the stress response to surgery, facilitates a rapid, smooth recovery and provides good post operative analgesia and sedation.

Methods: 135 patients of either sex, aged between 2 to 8 years, having body weight 10 to $30 \mathrm{~kg}$ belonging to ASA Grade I and II scheduled for infraumblical surgeries under GA were randomized into three groups of 45 each to receive the caudal block i.e Group A received .25\% levobupivacaine $(.75 \mathrm{ml} / \mathrm{kg}$ ) with $0.9 \% \mathrm{NS}$. Group B received $.25 \%$ levobupivacaine $(.75 \mathrm{ml} / \mathrm{kg})$ with fentanyl $1 \mathrm{mcg} / \mathrm{kg}$ diluted with $0.9 \% \mathrm{NS}$ upto $1 \mathrm{ml}$ and Group $\mathrm{C}$ received $0.25 \%$ levobupivacaine $(0.75 \mathrm{ml} / \mathrm{kg})$ with dexmedetomidine $1 \mathrm{mcg} / \mathrm{kg}$ diluted with $0.9 \% \mathrm{NS}$ upto $1 \mathrm{ml}$.

Results: There was statistically insignificant difference in the socio- demographic variables in terms of age, weight, sex ratio, ASA Grade and duration of surgery among the study groups. There was statistically significant $(p<0.05)$ prolongation in the duration of arousable sedation, recorded using the Ramsay sedation score in Group C(up to 4hrs), in contrast to Group A( up to $1 \mathrm{hrs}$ ) and Group B(up to 2hrs).

Conclusion: The mean ramsay sedation score was significantly greater in the group levobupivacaine with dexmedetomidine as compared to levobupivacaine alone and levobupivacaine with fentanyl group.

Keywords: Ramsay sedation score, Levobupivacaine, Dexmedetomidine, Caudal analgesia.

\section{Introduction:}

Pain is an unpleasant subjective sensation. Being subjective it can only be felt but cannot be fully expressed. Expression of pain is even more difficult in case of children who depend on their parents or care-givers for their well being. Post surgical pain is agonizing for the child and also causes the child to manipulate the operative site, occasionally leading to removal of dressing, drainage tubes or urinary catheters.

Uncontrolled postoperative pain resulting from any kind of surgery may produce a range of detrimental acute and chronic effects. Effective 
pain relief means smooth post operative period, increased patient compliance and early discharge from hospital.

In paediatric patients, regional anaesthesia is principally used for postoperative analgesia particularly caudal anaesthesia. The popularity of this procedure is due to clearly defined anatomical landmarks in children, safety, ease of technique and high success rate.

A single shot injection of LA through caudal space can provide analgesia for a limited period of time in the postoperative period so various adjuvants were added to local anaesthetic to prolong the duration of analgesia. Levobupivacaine, $S$ enantiomer of bupivacaine has anaesthetic activity with less cardiac and neural toxic effects than bupivacaine, while still possessing similar duration of sensory blockade ${ }^{1-}$ 3

Dexmedetomidine, a highly selective alpha-2 agonist, is under evaluation as neuraxial adjuvant as it provides stable hemodynamic parameters, good quality intraoperative and postoperative analgesia and arousable sedation with minimal side effects.

Fentanyl is a potent, short acting, highly lipophilic, synthetic opioid analgesic. It is commonly used as an adjuvant for postoperative analgesia with better hemodynamic stability.

With this background, we conducted the present study to compare the analgesic effects of caudal dexmedetomidine $V s$ fentanyl added to $0.25 \%$ levobupivacaine in children undergoing infraumblical surgeries under general anaesthesia.

\section{Methods}

After due permission from institutional ethics committee, this randomised, double blind interventional study was conducted on 135 children aged 2-8 years, of either sex, weighing 10 to $30 \mathrm{~kg}$, belonging to ASA Grade I and II undergoing infraumblical surgeries with informed parental consent. Patients with emergency surgery, parents refusal, infection at the site, delayed developmental milestones, neurological diseases, bleeding disorders were excluded from the study. Patients were randomly allocated into three groups using the sealed envelope method.

Group A(control group) received $0.25 \%$ levobupivacaine $0.75 \mathrm{ml} / \mathrm{kg}$ with $0.9 \%$ normal saline. Group B received $0.25 \%$ levobupivacaine $0.75 \mathrm{ml} / \mathrm{kg}$ with fentanyl $1 \mathrm{mcg} / \mathrm{kg}$ diluted upto $1 \mathrm{ml}$ with $0.9 \%$ normal saline. Group $\mathrm{C}$ received $0.25 \%$ levobupivacaine $0.75 \mathrm{ml} / \mathrm{kg}$ combined with dexmedetomidine $1 \mathrm{mcg} / \mathrm{kg}$ diluted upto $1 \mathrm{ml}$ with $0.9 \%$ normal saline. The patients were kept nil by mouth according to ASA guidelines for water (2hour), breast milk(4hour), and infant formula or meals(6 to 8hours).

A pre-anaesthesia check up was done 1 day prior to surgery and parents were explained about the anaesthetic technique. On arrival in OT routine non invasive monitors were attached and baseline parameters in form of systolic and diastolic $\mathrm{BP}, \mathrm{ECG}, \mathrm{SpO}_{2}$ were noted and drip started with Ringer lactate in the already placed cannula as per the institutional protocol.

Patients were premedicated with Inj. Glycopyrrolate $5 \mathrm{mcg} / \mathrm{kg}$ i.v., Inj Midazolam $.05 \mathrm{mg} / \mathrm{kg}$ i.v..

After preoxygenation with $100 \% \mathrm{O}_{2}$ for 3 minutes, induction was done with Inj. Thiopentone $5 \mathrm{mg} / \mathrm{kg}$ followed by $\mathrm{Inj}$. Atracurium $0.6 \mathrm{mg} / \mathrm{kg}$ i.v. Direct Laryngoscopy was done and patient was intubated with endotracheal tube of appropriate size. Bilateral air entry was checked and tube fixed.

Anaesthesia was maintained with $\mathrm{N}_{2} \mathrm{O}: \mathrm{O}_{2}$ $(60: 40)$, sevoflurane $(0.4-0.6 \%)$ and Inj. Atracurium $(0.15 \mathrm{mg} / \mathrm{kg}$ i.v.sos)

With all aseptic precautions, caudal block with $23 \mathrm{G}$ needle with $0.25 \%$ Levobupivacaine $0.75 \mathrm{ml} / \mathrm{kg}$ and study drug was administered in lateral decubitus position using standard loss of resistance technique after negative aspiration of blood and CSF. Hemodynamic parameters were recorded immediately after caudal block and thereafter every 5minutes throughout the surgery. 
At the end of surgery all anaesthetic agents were discontinued and patient was taken on 100\% 02 . On regaining spontaneous respiration, patient was reversed with Inj. Neostigmine $0.05 \mathrm{mg} / \mathrm{kg}$ and Inj. Glycopyrrolate $5 \mathrm{mcg} / \mathrm{kg}$ i.v. Patient was extubated when fully awake and breathing spontaneously and shifted to recovery room.

In post operative period, patient was assessed for sedation using Ramsay Sedation Score at $30 \mathrm{~min}, 1 \mathrm{hr}, 2 \mathrm{hr}, 4 \mathrm{hr}, 6 \mathrm{hr}, 9 \mathrm{hr}, 12 \mathrm{hr}, 18 \mathrm{hr}, 24 \mathrm{hr}$ (end point of study).

Statistical analysis
Statistical analysis was performed with the SPSS, version 21 for Windows statistical software package (SPSS inc., Chicago, IL, USA). The Categorical data was presented as numbers (percent) and were compared among groups using Chi square test. The quantitative data was presented as mean and standard deviation and were compared by students t-test. Probability was considered to be significant if less than 0.05 . $(p<0.05)$

Results

Table 1: Demographic data for the study group ( $\mathrm{N}=45$ )

\begin{tabular}{|c|c|c|c|c|c|c|c|c|}
\hline \multirow{3}{*}{$\begin{array}{l}\text { Patients } \\
\text { Characteristics }\end{array}$} & \multicolumn{6}{|c|}{ Mean士SD } & \multirow[t]{3}{*}{$P$ value } & \multirow[t]{3}{*}{ Significance } \\
\hline & \multicolumn{2}{|c|}{ Group A } & \multicolumn{2}{|c|}{ Group B } & \multicolumn{2}{|c|}{ Group C } & & \\
\hline & Mean & SD & Mean & SD & Mean & SD & & \\
\hline Age (years) & 3.91 & 1.33 & 4.44 & 1.79 & 3.77 & 1.15 & 0.072 & NS \\
\hline Weight (kg) & 13.36 & 3.27 & 14.75 & 3.55 & 14.21 & 3.16 & 0.140 & NS \\
\hline $\operatorname{Sex}(M / F)$ & \multicolumn{2}{|l|}{$36 / 9$} & \multicolumn{2}{|l|}{$34 / 11$} & \multicolumn{2}{|l|}{$40 / 5$} & 0.257 & NS \\
\hline $\begin{array}{l}\text { Duration of } \\
\text { Surgery }(\min )\end{array}$ & 32.67 & 4.47 & 34.34 & 6.35 & 34.42 & 6.51 & 0.294 & NS \\
\hline
\end{tabular}

NS-Not Significant

There was statistically insignificant difference in the socio- demographic variable in terms of age, weight, sex ratio, ASA Grade and duration of surgery among the study groups.

Table 2: Sedation Score

\begin{tabular}{|c|c|c|c|c|c|c|c|c|}
\hline \multirow{3}{*}{$\begin{array}{l}\text { Patients } \\
\text { Characteristics }\end{array}$} & \multicolumn{6}{|c|}{ Mean $\pm S D$} & \multirow[t]{3}{*}{ P value } & \multirow[t]{3}{*}{ Significance } \\
\hline & \multicolumn{2}{|c|}{ Group A } & \multicolumn{2}{|c|}{ Group B } & \multicolumn{2}{|c|}{ Group C } & & \\
\hline & Mean & SD & Mean & SD & Mean & SD & & \\
\hline $30 \mathrm{~min}$ & 4.98 & 0.45 & 5.77 & 0.47 & 5.97 & 0.14 & 0.0001 & $S$ \\
\hline $1 \mathrm{hr}$ & 3.56 & 0.50 & 4.75 & 0.53 & 5.26 & 0.71 & 0.0001 & $\mathrm{~S}$ \\
\hline $2 \mathrm{hr}$ & 2.64 & 0.53 & 3.52 & 0.69 & 4.37 & 0.61 & 0.0001 & $\mathrm{~S}$ \\
\hline $4 \mathrm{hr}$ & 1.29 & 0.55 & 2.60 & 0.72 & 3.37 & 0.64 & 0.0001 & $S$ \\
\hline $6 \mathrm{hr}$ & 1.00 & 0.00 & 1.00 & 0 & 2.42 & 0.69 & 0.0001 & $\mathrm{~S}$ \\
\hline
\end{tabular}

The above table shows the mean sedation scores postoperatively. There was statistically significant $(p<0.05)$ prolongation in the duration of arousable sedation, recorded using the Ramsay sedation score in Group C(up to 4hrs), in contrast to Group A( up to $1 \mathrm{hrs)}$ ) and Group B(up to $2 \mathrm{hrs}$ ). 


\section{DISCUSSION}

The greatest advance in paediatric pain medicine is the recognition that untreated pain is a significant cause of morbidity and mortality after surgical trauma. ${ }^{4}$ Several advances in developmental neurobiology and pharmacology, knowledge of new analgesics and newer applications of old analgesics in the last two decades have helped the anaesthesiologist in managing pain in children more efficiently. ${ }^{5}$ Prevention of pain whenever possible, using multimodal analgesia, has been shown to work well for nearly all cases and can be adapted for day cases, major cases, the critically ill child, or the very young.

Till date, various methods have been evolved for providing post operative pain relief in paediatric population, However, some methods have side effects which prohibit their use in children. For example, in children, narcotics could cause respiratory depression, oral analgesics cannot be given for some time after general anaesthesia due to fear of vomiting and aspiration, and fear of needle prick in the case of parenteral analgesics. A multimodal approach with inclusion of a regional anaesthetic technique is preferred.

Regional anaesthesia was not popular in paediatric patients previously but lately there has been growing interest in this field. Regional anaesthetic technique were underutilized in paediatric patients for three main reasons: lack of experience, fear of adverse effects and lack of patient cooperation. But now, increasing expertise in regional anaesthesia has made it more popular. Regional anaesthesia provides excellent post-operative analgesia and attenuation of stress response in children. It is safer, easier to perform and cost-effective, and should be used in all caseswhere possible. ${ }^{5}$

Caudal anaesthesia is one of the most commonly used regional anaesthesia techniques in paediatric age group. Caudal block is mostly given after induction of GA in children. It is a good, reliable and easy method to provide intraoperative and postoperative analgesia in the infraumblical surgery in paediatrics. ${ }^{6}$
One of the major limitations of the single shot caudal anaesthetic technique is a relative short duration of analgesia. Caudal catheters have increased risk of soiling and infections. Various additives such as Opioids, Ketamine and Clonidine have been studied to increase the duration and quality of caudal block with local anaesthetics. Problems such as nausea, respiratory depression, sedation and pruritis have limited their usefulness.

Bupivacaine is one of the most commonly used local anaesthetic in caudal block. Levobupivcaine, the S-enantiomer has significantly less cardiac and neural toxic effects than bupivacaine ${ }^{7}$, while still possessing a similarduration of sensory blockade ${ }^{8-9}$. The lower lipid solubility and greater intrinsic vasoactivity of the S-enantiomer also has the potential to produce differential neural blockade with less motor block ${ }^{10}$.

Fentanyl, a lipophilic opioid, is added frequently to local anaesthetics in children, but its beneficial effects are debated. Side effects like nausea, vomiting or respiratory depression, are not uncommon. It was observed in the study done by Doctor TP et al conducted a study to compare the effectiveness of caudal $0.25 \%$ ropivacaine with $0.25 \%$ bupivacaine with fentanyl in 112 paediatric patients undergoing infraumblical surgeries and concluded that ropivacaine with fentanyl was a better combination as an to GA. ${ }^{11}$ Similarly, A study was done by Swapnadeep Sengupta et al who compared the postoperative analgesic efficacy of caudal bupivacaine with fentanyl and ropivacaine with fentanyl in 60 paediatric patients undergoing infraumblical surgeries. They concluded that fentanyl when added to ropivacaine prolonged the duration of postoperative analgesia with shorter duration of motor blockade. ${ }^{12}$

Dexmedetomidine is a potent and highly selective alpha2 adrenergic agonist which is safe and effective additive in many anaesthetic implications and analgesic techniques. Fares KM et al concluded that the dexmedetomidine as adjuvant achieved significant postoperative pain relief with prolonged arousable sedation. ${ }^{13}$ 
Tong $\mathrm{Y}$ et al published a meta-analysis on Analgesic effect and adverse events of dexmedetomidine as additive for paediatric caudal anaesthesia and concluded that dexmedetomidine as additive to local anesthetic provides a significant longer postoperative analgesia. $^{14}$

The children in our study belonged to age group 2-8years. The male:female ratio in the three groups were also comparable. There was no statistically significant difference among the groups with regards to Age, Sex and Weight. This helped us to judge the clinical significance of our study as the distribution, metabolism, excretion and action of drugs are undoubtedly varied in different age groups. Also pain perception can vary according to age and sex. Therefore, clinically insignificant variation in age, sex and weight simply helped to alleviate these confounding factors. Our study validates the findings of Neelam Dogra et al who compared the effects of Caudal Levobupivacaine, tramadol and a combination of both to pain in 78 paediatric patients undergoing Inguinal herniotomy. They also found that all groups were comparable with regards to demographic parameters age, sex and weight. ${ }^{15}$

The mean duration of surgery was around 32 minutes in group A and 34 minutes in Group B and $C$. The duration of surgery was comparable in all the three groups and no statistically significant difference was observed. This avoided any discrepancy in duration of anaesthesia among the groups. Our findings also match with the results of Hossam A. El Shamma et al who compared the effect of caudal dexmedetomidine versus morphine added to bupivacaine in 50 paediatric patients undergoing infraumblical surgeries. They found no significant differences in demographic data and duration of surgery. ${ }^{16}$

Similar results were observed in the study done by Elfawal et al who also found that the result of demographic data and duration of surgery were comparable among the study groups when they compared the effects of caudal levobupivacaine with fentanyl and levobupivacaine with dexmedetomidine in 90 children undergoing orthopedic lower limb surgery ${ }^{17}$

Patients receiving dexmedetomidine adjuvant showed higher Ramsay Sedation Score, denoting longer arousable sedation compare to other two groups.

Our study validates the finding of Fares et al who conducted a study to investigate the effect of addition of dexmedetomidine to $0.25 \%$ bupivacaine for caudal analgesia $(1 \mathrm{ml} / \mathrm{kg})$ in 40 children undergoing major abdominal cancer surgery. They found that addition of dexmedetomidine $(1 \mathrm{mcg} / \mathrm{kg})$ to caudal bupivacaine $0.25 \%$ achieved significant postoperative pain relief with less use of postoperative analgesics and prolonged duration of arousable sedation. ${ }^{13}$

Similarly, Anand et al. have concluded that caudal dexmedetomidine $(2 \mu \mathrm{g} / \mathrm{kg}$ ) with $0.25 \%$ ropivacaine $(1 \mathrm{ml} / \mathrm{kg})$ for pediatric lower abdominal surgeries achieved significant postoperative pain relief that resulted in a better quality of sleep and a prolonged duration of arousable sedation and produced less incidence of emergence agitation following sevoflurane anesthesia. $^{18}$

Our study goes in hand in hand with the study done by Abdel Aziz et al who used sedation score and concluded that arousable sedation was prolonged in levobupivacaine-fentanyl and levobupivacaine-dexmedetomidine group as compared to levobupivacaine alone. ${ }^{19}$

\section{Conclusion}

The mean ramsay sedation score was significantly greater in the group levobupivacaine with dexmedetomidine as compared to levobupivacaine alone and levobupivacaine with fentanyl group. So dexmedetomidine can be considered as a suitable adjuvant to levobupivacaine for caudal block as it produces arousable sedation with minimal side effects.

Financial support and sponsorship-nil

Conflicts of interest- There are no conflicts of interest

\section{References}

1. International Association for Study of Pain, subcommittee in taxonomy.Pain terms: a list 
with definition and notes on usage. Pain 1979, 6:249-52.

2. Morgan GE, Mikhail Ms, Murray MJ. Clinical anaesthesiology. $4^{\text {th }}$ edition; USA :McGraw Hill;2006

3. Carr DB, Goudas LC. Acute pain. Lancet 1999; 353:2051-62.

4. Cravero JP, Kain ZV; Pediatric Anaesthesia. In Barash PG, Cullen BF, Steeling RK, Cahalan $\mathrm{KM}$, Stock CM(ed). Clinical Anesthesia, $6^{\text {th }}$ edition, PhiladelphiaPA: Lippincott Williams and Wilkins; 2009; 1216.

5. Ivan, Negron PD, Lonnqvist PA, Eksborg S, Mosseti V, Grosseti R, Italiano $S$ et al; Acomparison of three different Concentrations of Levobupivacaine for caudal block in children. AnesthAnalg2003;97:368-371.

6. Ahmed A.Abd El Aziz ${ }^{1}$ Fentanyl, dexmedetomidine, dexamethasone as adjuvant to local anesthetics in caudal analgesia in pediatrics: A comparative study. 2013 May-Aug; 7(2): 212-215.

7. Chang DH, Ladd LA, Wilson KA, Gilgor L, Mather LE, Tolerability of large dose intravenous levobupivacaine in sheep. AnaesthAnalg. 2000; 91 :671-679.

8. Cox CR, Faccenda KA, Gilhooly C, Bannister J, Scott NB, Morrison LMM. Extradural S(-) Bupivacaine : comparison with RSbupivacaine. Br J Anaesth. 1998;80:289-293.

9. Foster $\mathrm{RH}$, Markham A. Levobupivacaine: a review of its pharmacology and use as local anaesthestic. Drugs. 2000;59:551-579.

10. Breschan $C$, Jost $R$, Krumphholz $R$ et al. $A$ prospective study comparing the analgesic efficacy of levobuoivacaine, ropivacaine and bupivacaine in pediatric patients undergoing caudal blockade. PediatrAnesth 2005; 15: 301-306.

11. Tarlika P. Doctor, Divyang B. Dalwadi, Lissa Abraham, Namrata Shah, Indu A. Chadha, and Bharat J. ShahComparison of ropivacaine and bupivacaine with fentanyl for caudal epidural in pediatric surgery.
Anesth Essays Res. 2013 May-Aug; 7(2): 212-215.

12. Swapnadeep Sengupta, Sudakshina Mukherji, Jagabandhu Sheet, Anamitra Mandal, and SarbariSwaika. Caudal-epidural bupivacaine versus ropivacaine with fentanyl for paediatric postoperative analgesia. Anesth Essays Res. 2015 May-Aug; 9(2): 208-212.

13. Fares $\mathrm{KM}$, Othman $\mathrm{AH}$, AliedinNH.Efficacy and safety of dexmedetomidine added to caudal bupivacaine. Pain Physician. 2014Sept-Oct;17(5):393-400

14. Tong $Y$, Ren $H$, Ding $X$, Jin $S$, Chen $Z$, Li $Q$. Analgesic effect and adverse events of dexmedetomidine as additive for pediatric caudal anesthesia: a meta-analysis. PaediatrAnaesth. 2014 Dec;24(12):1224-30

15. Dogra N, Dadheech R, Dhaka M, Gupta A. A study to compare caudal levobupivacaine, tramadol and a combination of both in paediatric inguinal hernia surgeries. Indian J Anaesth2018;62:359-65

16. Hossam A. El Shamaa and Mohamed IbrahimA comparative study of the effect of caudal dexmedetomidine versus morphine added to bupivacaine in pediatric infraumbilical surgery. Saudi J Anaesth. 2014 AprJun; 8(2): 155-160.

17. SM Elfawal, WA Abdelaal, MR Hosny.Comparison of fentanyl and dexmedetomidine to levobupivacaine for caudal analgesia.Saudi journal of anaesthesia 2016(10)4:423-427

18. Gristwood RW. Cardiac and CNS toxicity of levobupivacaine: Strengths of evidence for advantage over bupivacaine. Drug Saf2002;25:153-63.

19. Abdel Aziz MM, Abdelfatah AM, Abdel Hamid HM. Ultrasound-guided caudal analgesia using fentanyl versus dexmedetomidine as an adjuvant for levobupivacaine in infraumbilical pediatric surgeries. Ain-Shams J Anaesthesiol2016; 9:542- 